\title{
GAMBARAN KEMANDIRIAN EKONOMI PADA LANSIA
}

\section{Overview of Economic Independence in the Elderly}

\author{
Yeremia Rante Ada ${ }^{1)}$, Mujahidatul Musfiroh'), Desiderius Priyo S ${ }^{3)}$, Vinc H. Wiyono ${ }^{4)}$ \\ 1,2,3,4) Pusat Penelitian Kependudukan LPPM UNS, Jl. Ir. Sutami 36 A Kentingan Surakarta \\ email : yeremia_ada@staff.uns.ac.id
}

\begin{abstract}
ABSTRAK
Latar Belakang: Kemandirian ekonomi lansia merupakan kemampuan lansia untuk memenuhi kebutuhan ekonomi lansia dengan tidak bergantung pada orang lain. Penelitian ini bertujuan untuk mengetahui karakteristik lanjut usia dan gambaran kemandirian ekonomi pada salah satu kelompok lansia di kelurahan Mojosongo.

Metode: Penelitian ini menggunakan metode deskriptif. Jumlah sampel penelitian yaitu 56 responden lansia yang hadir pada kegiatan Posyandu Lansia di Kelurahan Mojosongo Kota Surakart. Sampel dalam penelitian ini diperoleh dengan menggunakan teknik random sampling. Teknik pengumpulan data menggunakan teknik wawancara, observasi, dokumentasi, catatan lapangan, dan kepustakaan.

Hasil: Hasil penelitian menunjukkan bahwa 61\% responden berusia sekitar 56-65 tahun, 55\% responden berjenis kelamin perempuan, $75 \%$ responden masih aktif bekerja, $75 \%$ responden memiliki penghasilan $<\mathrm{Rp} 1.802 .700,50 \%$ responden memiliki pengeluaran setiap bulan berkisar Rp 1.000.000-1.500.000 dengan jenis pengeluaran terbesar (84\%) untuk memenuhi kebutuhan akan makanan dan kebutuhan lainnya seperti listik, air dan Rukun Tetangga, $77 \%$ responden tidak memiliki usaha dan $52 \%$ tidak memiliki jenis keterampilan tertentu.

Simpulan: Gambaran ekonomi responden sudah baik. Banyak responden yang masih bekerja. Namun penghasilan yang diperoleh masih dibawah Upah Minimal Regional (UMR). Upaya pemenuhan kebutuhan ekonomi lansia tidak didukung dengan kepemilikan usaha dan ketrampilan lansia. Sehingga responden hanya bergantung pada pekerjaan yang upahnya masih dibawah UMR.
\end{abstract}

Kata Kunci: Lansia, Kemandirian ekonomi 


\section{ABSTRACT}

Background: The economic independence of the elderly is the ability of the elderly to meet the economic needs of the elderly inappropriately to others. This research discusses the characteristics of the elderly and discusses economic independence in one of the elderly groups in Mojosongo village.

Methods: This research used a descriptive method. The number of research samples was 56 elderly respondents who attended the Elderly Posyandu activities in Mojosongo SubDistrict, Surakart City. The sample in this study was obtained using random sampling techniques. Data collection techniques using interview techniques, observation, documentation, field notes, and literature.

Results: The results showed that $61 \%$ of respondents chose about $56-65$ years, $55 \%$ of respondents were female, $75 \%$ of respondents were still actively working, $75 \%$ of respondents had conversations $<R p$ 1,802,700, 50\% of respondents had $R p$ 1,000 per month. 000-1,500,000 with special types (84\%) to meet food needs and needs such as electricity, air and neighborhood units, $77 \%$ of respondents do not have a business and $52 \%$ do not have any type of special assistance.

Conclusion: The economic picture of the respondents is good. Many respondents still work. The minimum wage obtained is still a Regional Minimum Wage (UMR). Efforts to fulfill the economic needs of the elderly are not supported by the efforts and skills of the elderly. Accepting respondents only depends on jobs whose wages are still below the UMR.

Keywords: Elderly, economic independence

\section{PENDAHULUAN}

Lansia adalah salah satu kelompok masyarakat yang lemah dan tidak memiliki daya, kekuatan atau kemampuan mengakses sumber daya produktif atau masyarakat terpinggirkan dalam pembangunan. Lansia adalah kelompok masyarakat yang mengalami penurunan keterbatasan fisik karena proses penuaan, namun beberapa lansia masih dapat melakukan aktivitas mandiri sesuai dengan kemampuan yang dimiliki. Jumlah Lansia yang semakin meningkat perlu mendapat perhatian terutama bagi lansia yang masih memiliki kemandirian dalam beraktivitas untuk dapat dioptimalkan sumber daya yang dimiliki sesuai dengan kemampuannya. Kemandirian merupakan kemampuan individu untuk memenuhi kebutuhan hidup dengan tidak bergantung pada orang lain. Kemandirian juga berarti suatu keadaan dimana seseorang berupaya untuk memenuhi segala tuntutan.

Hasil penelitian ini nantinya diharapkan sebagai data awal (Gambaran awal) untuk pengembangan ipteksosbud yang terkait dengan masalah lansia terutama dalam menggalakkan upaya-upaya pemberdayaan pada kelompok lansia selanjutnya sehingga tercipta kelompok lansia yang mandiri, berkualitas dan produktif secara sosial maupun ekonomi, serta upaya menjaga para lansia tetap hidup sehat, bahagia dan sejahtera, tangguh, sesuai dengan martabat kemanusiaan.

Berdasarkan hasil survey penduduk Indonesia oleh Badan Pusat Statistik (BPJS) tahun 2010 memiliki jumlah penduduk sebesar 253,60 juta jiwa, dan berdasarkan hasil survey tersebut menunjukkan kecenderungan penambahan jumlah penduduk lansia. Pada tahun 2015 terdapat 21,8 juta jiwa lansia dan terus meningkat pada tahun 2016 menjadi 22,6 juta jiwa dan sampai akhir 2018 diprediksi jumlah penduduk lansia mencapai 24 juta jiwa. Diperkirakan untuk tahun 2020 Indonesia akan memiliki lansia sebesar 11.3 persen dari jumlah penduduk. Isu penambahan lansia ini menjadi isu strategis yang harus diperhatikan agar jangan sampai penambahan penduduk lansia menjadi beban 
bagi keluarga, masyarakat dan pemerintah. Menjadi kewajiban mulai saat ini adalah menggalakkan upaya-upaya untuk menjaga para lansia tetap hidup sehat, bahagia dan sejahtera, tangguh, mandiri, berkualitas dan produktif secara sosial maupun ekonomi sesuai dengan martabat kemanusiaan $^{[1]}$. Undang-Undang No 13 Tahun 1998 tentang kesejahteraan lansia menetapkan, bahwa batasan umur lansia di Indonesia adalah 60 tahun ke atas. Kelompok umur lansia: 50-64 tahun dan 65 tahun keatas ${ }^{[2]}$. Lansia berisiko tinggi untuk menderita berbagai penyakit degeneratif (usia >65 tahun). Kelompok dengan kategori lansia merupakan kelompok yang mengalami proses penuaan (aging process).

Kemandirian merupakan kemampuan individu untuk memenuhi kebutuhan hidup dengan tidak bergantung pada orang lain. Kemandirian juga berarti suatu keadaan dimana seseorang berupaya untuk memenuhi segala tuntutan. Keberdayaan masyarakat yang ditandai adanya kemandiriannya dapat dicapai melalui proses pemberdayaan masyarakat. Keberdayaan masyarakat dapat diwujudkan melalui partisipasi aktif masyarakat yang difasilitasi dengan adanya pelaku pemberdayaan. Sasaran utama pemberdayaan masyarakat adalah mereka yang lemah dan tidak memiliki daya, kekuatan atau kemampuan mengakses sumberdaya produktif atau masyarakat terpinggirkan dalam pembangunan. Tujuan akhir dari proses pemberdayaan masyarakat adalah untuk memandirikan warga masyarakat agar dapat meningkatkan taraf hidup keluarga dan mengoptimalkan sumberdaya yang dimilikinya $^{[3]}$.

Lansia adalah salah satu kelompok masyarakat yang lemah dan tidak memiliki daya, kekuatan atau kemampuan mengakses sumberdaya produktif atau masyarakat terpinggirkan dalam pembangunan. Lansia adalah kelompok masyarakat yang mengalami penurunan keterbatasan fisik karena proses penuaan, namun beberapa lansia masih dapat melakukan aktivitas mandiri sesuai dengan kemampuan yang dimiliki. Jumlah Lansia yang semakin meningkat perlu mendapat perhatian terutama bagi lansia yang masih memiliki kemandirian dalam beraktivitas untuk dapat dioptimalkan sumber daya yang dimiliki sesuai dengan kemampuannya.

Berdasarkan hal tersebut, penelitian gambaran awal tentang kemandirian ekonomi lansia dilakukan sebagai upaya awal untuk mengetahui sumber daya yang dimiliki lansia untuk dapat dioptimalkan sesuai dengan kemampuannya.

\section{SUBJEK DAN METODE}

Jenis penelitian ini adalah penelitian observasional deskriptif dengan pendekatan time point approach untuk mengetahui gambaran kemandirian ekonomi pada salah satu kelompok lansia di Kelurahan Mojosongo Surakarta.

Populasi dalam penelitian ini adalah 125 orang lansia berusia 46 - >65 tahun yang ada di salah satu kelompok lansia di kelurahan Mojosongo. Kategori lansia: masa lansia awal dengan usia 46-55 tahun, masa lansia akhir 56-65 tahun dan masa manula $>65$ tahun $^{[4]}$. Pengambilan sampel secara Simple Random Sampling, yaitu pengambilan sampel dari populasi secara acak tanpa memperhatikan strata yang ada dalam populasi itu ${ }^{[5]}$. Pengambilan sampel penelitian diambil $10 \%-20 \%$ dari besar populasi jika besar populasi $<10.000^{[6]}$.

Teknik pengambilan sampel menggunakan rumus dari Taro Yamane atau Solvin ${ }^{[7]}$, berdasarkan rumus diperoleh sampel sejumlah $55.5 \approx 56$ orang. Instrumen dalam penelitian ini adalah kuesioner untuk mengetahui karakteristik responden dan kemandiriant ekonomi responden. Pengumpulan data dilakukan melalui observasi, wawancara, dan penyebaran kuesioner dengan pendampingan kepada responden. Analisis data dengan analisis deskriptif (Univariat).

HASIL DAN PEMBAHASAN

Salah satu kelompok lansia yang ada di Kelurahan Mojosongo adalah kelompok 
lansia yang terdapat di RW 09. Kegiatan rutin diselenggarakan pada kelompok lansia di RW 09 Kelurahan Mojosongo yaitu: 1. Penimbangan berat badan dan pengukuran tinggi badan

2. Pemeriksaan tekanan darah

3. Pemberian makanan tambahan

Secara rutin aktivitas ini diselenggarakan satu kali dalam setiap bulan pada Jumat terakhir. Hasil penimbangan dan pengukuran tekanan darah secara rutin dipantau melalui Kartu Menuju Sehat (KMS) khusus Lansia. Kegiatan lansia di RW 09 Kelurahan Mojosongo dibawah pantauan Puskesmas setempat. Jumlah anggota lansia di RW 09 sekitar 125 orang.

Berdasarkan hasil penelitian yang telah dilakukan pada kelompok lansia di salah satu kelompok lansia yang ada di kelurahan Mojosongo diperoleh gambaran karakteristik responden sebagai berikut:

\section{Umur Responden}

Tabel 1. Distribusi Frekuensi Berdasarkan Umur

\begin{tabular}{|c|c|c|}
\hline $\begin{array}{l}\text { Rentang } \\
\text { Umur } \\
\text { (Tahun) }\end{array}$ & $\begin{array}{c}\text { Frekuensi } \\
\text { (Orang) }\end{array}$ & $\begin{array}{c}\text { Persentase } \\
(\%)\end{array}$ \\
\hline $46-55$ & 4 & 7 \\
\hline $56-65$ & 34 & 61 \\
\hline$>65$ & 18 & 32 \\
\hline Total & 56 & 100 \\
\hline
\end{tabular}

peroleh gambaran bahwa pada kelompok lansia ini sebagian besar (61 persen) berusia sekitar 56-65 tahun kemudian disusul oleh lansia yang berumur diatas 65 tahun. Hanya sebagian kecil saja (7 persen) yang berusia 46-55 tahun.

Kategori lansia: masa lansia awal dengan usia 46-55 tahun, masa lansia akhir 56-65 tahun dan masa manula >65 tahun $^{[4]}$. Organisasi kesehatan dunia (WHO) mengolongkan lanjut usia menjadi 4 yaitu: usia pertengahan (middle age) 45 59 tahun, lanjut usia (elderly) 60-74 tahun, lanjut usia tua (old) 75-90 tahun dan usia sangat tua (very old) diatas 90 tahun, sedangkan menurut Priyitno dalam Aryo (2002) mengatakan bahwa setiap orang yang berhubungan dengan lanjut usia adalah orang yang berusia 56 tahun ke atas, tidak mempunyai penghasilan dan tidak berdaya mencari nafkah untuk keperluan pokok bagi kehidupan sehari-hari, Saparinah (1983) berpendapat bahwa pada usia 55 sampai 65 tahun merupakan kelompok umur yang mengalami berbagai penurunan daya tahan tubuh/kesehatan dan berbagai tekanan psikologis. Dengan demikian akan timbul perubahan-perubahan dalam hidupnya. Demikian juga batasan lanjut usia yang tercantum dalam Undang-Undang No.4 tahun 1965 tentang pemberian bantuan penghidupan orang jompo, bahwa yang berhak mendapatkan bantuan adalah mereka yang berusia 56 tahun ke atas. Dengan demikian dalam undang-undang tersebut menyatakan bahwa lanjut usia adalah yang berumur 56 tahun ke atas ${ }^{[8]}$.

\section{Jenis Kelamin}

Tabel 2. Distribusi Frekuensi Berdasarkan Jenis Kelamin

\begin{tabular}{ccc}
\hline $\begin{array}{c}\text { Jenis } \\
\text { Kelamin }\end{array}$ & $\begin{array}{c}\text { Frekuensi } \\
\text { (Orang) }\end{array}$ & $\begin{array}{c}\text { Persentase } \\
(\boldsymbol{\%})\end{array}$ \\
\hline Laki-laki & 25 & 45 \\
Perempuan & 31 & 55 \\
\hline Total & 56 & 100 \\
\hline
\end{tabular}

Berdasarkan pada tabel 2 diatas diperoleh gambaran bahwa pada kelompok lansia ini sebagian besar adalah perempuan (55 persen). Hanya sebagian kecil (45 persen) yang berjenis kelamin lakilaki. Hal ini menunjukkan bahwa usia harapan hidup perempuan lebih tinggi daripada laki-laki.

Survei Sosial Ekonomi Nasional mulai tahun 2009 oleh Badan Pusat Statistik, jumlah perempuan lansia sebanyak 10,4 juta jiwa, sedangkan laki-laki 8,8 juta jiwa. Fenomena itu disebabkan usia harapan hidup perempuan di Indonesia (71 tahun), lebih tinggi dibandingkan dengan laki-laki (67 tahun) ${ }^{[9]}$. Dengan demikian kondisi ini juga menunjukkan bahwa lansia dengan jenis kelamin perempuan perlu mendapat perhatian khusus. 


\section{Status Tinggal}

Berdasarkan pada tabel 3 diperoleh gambaran bahwa sebagian besar lansia pada kelompok ini tinggal bersama suami atau isteri (pasangan hidup) dan bersama anggota keluarga lainnya. Lansia yang tinggal bersama pasangan dan anggota keluarga yang lain umumnya masih bekerja untuk memenuhi kebutuhan sehari-hari

Tabel 3. Distribusi Frekuen dan masih ikut membantu menopang kebutuhan ekonomi keluarga, sebagian kecil dibantu oleh anggota keluarga yang lain terutama anak. Namun masih ada sebagian kecil (7 persen) lansia tinggal sendiri. Umumnya lansia yang tinggal sendiri adalah lansia yang berumur 56-65 tahun dan bekerja untuk menopang kebutuhan sehari-hari.

\begin{tabular}{lcc}
\hline \multicolumn{1}{c}{ Status tinggal } & $\begin{array}{c}\text { Frekuensi } \\
\text { (Orang) }\end{array}$ & $\begin{array}{c}\text { Persentase } \\
(\boldsymbol{\%})\end{array}$ \\
\hline Bersama suami/isteri & 26 & 46 \\
$\begin{array}{l}\text { Bersama anggota keluarga } \\
\text { yang lain (Anak, cucu) }\end{array}$ & 26 & 46 \\
Sendiri & 4 & 7 \\
\hline \multicolumn{1}{c}{ Total } & 56 & 100
\end{tabular}

4. Status Pekerjaan

Tabel 4. Distribusi Frekuensi
Berdasarkan Status Pekerjaan

\begin{tabular}{lcc}
\hline $\begin{array}{c}\text { Status } \\
\text { Pekerjaan }\end{array}$ & $\begin{array}{c}\text { Frekuensi } \\
\text { (Orang) }\end{array}$ & $\begin{array}{c}\text { Persentase } \\
(\%)\end{array}$ \\
\hline $\begin{array}{l}\text { Masih } \\
\text { bekerja }\end{array}$ & 42 & 75 \\
$\begin{array}{l}\text { Tidak } \\
\text { bekerja }\end{array}$ & 14 & 25 \\
\hline Total & 56 & 100 \\
\hline
\end{tabular}

Berdasarkan pada tabel 4 diatas diperoleh gambaran bahwa sebagian besar (75 persen) lansia masih bekerja. Lansia yang bekerja ini umumnya dengan penghasilan yang tidak menentu untuk menopang kebutuhan utama keluarga (kebutuhan akan makanan). Lansia yang masih bekerja adalah yang belum memasuki masa pensiun. Hanya sebagian kecil (25 persen) lansia yang tidak bekerja. Umumnya lansia yang tidak bekerja adalah lansia yang telah purnakarya (pensiun) kemudian lansia yang memang sebagai ibu rumah tangga (sebelumnya tidak bekerja). Dalam memenuhi kebutuhan pokok sehari-hari (kebutuhan akan makanan), dipenuhi dari gaji pensiun setiap bulannya dan dari anggota keluarga lain (pasangan atau anak) yang tinggal bersama.

\section{Aktivitas (Pekerjaan) Lansia}

Berdasarkan pada tabel 5 diperoleh gambaran bahwa sebagian besar lansia masih beraktivitas (bekerja). Sebagian besar (34 persen) jenis aktivitas (pekerjaan) sebagai pedagang/berjualan atau membuka usaha sendiri. Hanya sebagian kecil (masing-masing 13 persen) yang sudah pensiun/purnakarya dan tidak bekerja atau membantu aktivitas keluarga di rumah. Jenis aktivitas (pekerjaan) sebagai pedagang (berjualan, usaha kecil lainnya), Tukang kayu/bangunan, becak, serabutan, kuli, buruh bangunan umumnya tidak memiliki penghasilan yang tetap setiap hari, namun setiap bulannya masih dapat cukup untuk memenuhi kebutuhan pokok (kebutuhan akan makanan). Sebagian lansia masih aktif bekerja sebagai buruh pabrik, supir, tenaga honoror, guru, PNS, pembantu rumah tangga dengan penghasilan tetap setiap bulan untuk mencukupi kebutuhan pokok. Bagi lansia yang sudah pensiun/purnakarya umumnya menggunakan uang pensiun untuk memenuhi kebutuhan pokok sehari-hari. Sedangkan yang tidak bekerja atau beraktivitas di rumah memenuhi kebutuhan pokok dari bantuan anggota keluarga yang masih bekerja. 
Tabel 5. Distribusi Frekuensi Aktivitas (Pekerjaan) Lansia

\begin{tabular}{lcc}
\hline Jenis Pekerjaan & $\begin{array}{c}\text { Frekuensi } \\
\text { (orang) }\end{array}$ & $\begin{array}{c}\text { Persentase } \\
(\%)\end{array}$ \\
\hline Usaha (Pedagang/Berjualan, penjahit) & 19 & 34 \\
Tukang kayu/bangunan, becak, & 7 & 13 \\
serabutan, kuli, buruh bangunan & 9 & 16 \\
Buruh pabrik, sopir & 4 & 7 \\
Tenaga Honorer, Guru, PNS & 3 & 5 \\
Pembantu Rumah Tangga & 7 & 13 \\
Pensiun/Purnakarya & 7 & 13 \\
Tidak bekerja, momong cucu, ibu & & \\
rumah tangga & 56 & 100 \\
\hline Total & \multicolumn{2}{|}{}
\end{tabular}

6. Gambaran Penghasilan Lansia Tabel 6. Deskripsi Rata-rata Penghasilan Lansia

\begin{tabular}{ccc}
\hline $\begin{array}{c}\text { Rata-rata } \\
\text { Penghasilan } \\
\text { (Rp) }\end{array}$ & $\begin{array}{c}\text { Frekuensi } \\
\text { (Orang) }\end{array}$ & $\begin{array}{c}\text { Persentase } \\
(\%)\end{array}$ \\
\hline$<1.802 .700$ & 42 & 75 \\
$\geq 1.802 .700$ & 14 & 25 \\
\hline Total & 56 & 100 \\
\hline Pada tabel & 6 diatas terlihat bahwa
\end{tabular}
sebagian besar ( 75 persen) lansia memiliki rata-rata peghasilan < $\mathrm{Rp} 1.802 .700$. Hanya sebagian kecil saja ( 25 persen) lansia yang memiliki penghasilan $\mathrm{Rp} 1.802 .700$ atau lebih.

Besarnya Upah Minimum Regional (UMR) maupun Upah Minimum Kota/Kabupaten Surakarta 2019 adalah Rp 1.802.700. Dengan demikian dapat terlihat bahwa sebagian besar lansia masih memiliki penghasilan dibawah atau kurang dari Upah Minimum Kota/Kabupaten Surakarta 2019.

\begin{tabular}{lcc}
$\begin{array}{l}\text { 7. Rata-Rata } \\
\text { Setiap Bulan }\end{array}$ & Pengeluaran & Lansia \\
$\begin{array}{l}\text { Tabel 7. } \\
\text { Pengeluaran Lansia }\end{array}$ & Deskripsi & Rata-rata \\
\hline $\begin{array}{l}\text { Rata-rata } \\
\text { Pengeluaran } \\
\text { (Rp) }\end{array}$ & $\begin{array}{c}\text { Frekuensi } \\
\text { (Orang) }\end{array}$ & $\begin{array}{c}\text { Persentas } \\
\text { e } \\
(\boldsymbol{\%})\end{array}$ \\
\hline $\begin{array}{l}\text { (O) } \\
1.000 .000\end{array}$ & 16 & 29 \\
$\begin{array}{l}1.000 .000- \\
1.500 .000\end{array}$ & 28 & 50 \\
$>1.500 .000$ & 12 & 21 \\
\hline Total & 56 & 100 \\
\hline
\end{tabular}

Berdasarkan pada tabel 7, diperoleh gambaran bahwa sebagian besar (50 persen) lansia memiliki rata-rata pengeluaran setiap bulannya sebesar Rp 1.000.0001.500.000. Sebagian besar lansia yang memiliki rata-rata pengeluaran sebesar $\mathrm{Rp}$ 1.000.000-1.500.000 ini adalah mereka yang memiliki rata-rata penghasilan $\mathrm{ku}-$ rang dari atau sama dengan Rp 1.500.000. Hanya sebagian kecil saja (21 persen) yang mempunyai pengeluaran lebih dari Rp 1.500.000. Sebagian besar lansia yang memiliki rata-rata pengeluaran lebih dari Rp 1.500.000 ini adalah mereka yang memiliki rata-rata penghasilan lebih dari $\mathrm{Rp}$ 1.500.000. Dengan demikian dapat diperoleh gambaran bahwa pada sebagian besar lansia melakukan upaya agar pengeluaran disesuaikan/dicukupkan sesuai dengan penghasilan yang telah diperoleh setiap bulannya.

8. Deskripsi Jenis Pengeluaran

Tabel 8. Deskripsi Jenis Pengeluaran

\begin{tabular}{lcc}
\hline $\begin{array}{c}\text { Jenis } \\
\text { Pengeluaran }\end{array}$ & $\begin{array}{c}\text { Frekuensi } \\
\text { (Orang) }\end{array}$ & $\begin{array}{c}\text { Persentase } \\
(\%)\end{array}$ \\
\hline $\begin{array}{l}\text { Makan dan } \\
\text { kebutuhan }\end{array}$ & 47 & 84 \\
lainnya \\
(listrik, air, & & \\
RT, & & \\
Sosial & 6 & 11 \\
Sekolah anak & 2 & 4 \\
Berobat & 1 & 2 \\
\hline Total & 56 & 100 \\
\multicolumn{3}{c}{ Berdasarkan pada tabel 8 nampak } \\
bahwa sebagian besar (84 persen) jenis \\
pengeluaran lansia adalah untuk memenu-
\end{tabular}


hi kebutuhan akan makanan dan kebutuhan lainnya seperti listik, air dan Rukun Tetangga. Selebihnya melakukan pengeluaran terbanyak untuk dana sosial (11 persen), untuk kebutuhan anak sekolah 4 persen dan hanya 2 persen yang memprioritaskan untuk dana berobat.

Hal ini menunjukkan bahwa sebagian besar lansia masih memprioritaskan penghasilan yang diperolehnya untuk memenuhi kebutuhan primer. Hal ini terjadi karena penghasilan yang diperoleh terbatas dan hanya cukup untuk memenuhi kebutuhan primer saja sebagai yag pokok dalam kehidupan.

\section{Deskripsi Kepemilikan Usaha}

Tabel 9. Deskripsi Kepemilikan Usaha

\begin{tabular}{ccc}
\hline $\begin{array}{c}\text { Memiliki } \\
\text { Usaha }\end{array}$ & $\begin{array}{c}\text { Frekuensi } \\
\text { (Orang) }\end{array}$ & $\begin{array}{c}\text { Persentase } \\
(\mathbf{\%})\end{array}$ \\
\hline Ya & 13 & 23 \\
Tidak & 43 & 77 \\
\hline Total & 56 & 100
\end{tabular}

Berdasarkan pada tabel 9 diatas diketahui bahwa sebagian besar (77 persen) lansia tidak memiliki usaha. Sebagian besar lansia yang tidak memiliki usaha karena adanya keterbatasan baik dalam hal kemampuan karena keterbatasan fisik dan keterampilan maupun karena finansial untuk permodalan. Hanya sebagian kecil saja (23 persen) lansia yang memiliki usaha. Jenis usaha yang dimiliki oleh lansia sebagian besar adalah usaha dagang dan jasa.

\section{Deskripsi Keterampilan yang Dimiliki}

Tabel 10. Deskripsi Keterampilan yang Dimiliki

\begin{tabular}{ccc}
\hline $\begin{array}{c}\text { Memiliki } \\
\text { Keterampilan }\end{array}$ & $\begin{array}{c}\text { Frekuensi } \\
\text { (Orang) }\end{array}$ & $\begin{array}{c}\text { Persentase } \\
(\boldsymbol{\%})\end{array}$ \\
\hline Ya & 27 & 48 \\
Tidak & 29 & 52 \\
\hline Total & 56 & 100
\end{tabular}

Tabel 10 diatas menunjukkan bahwa sebagian besar (52 persen) lansia tidak memiliki jenis keterampilan tertentu. Selain karena faktor usia juga karena keterbatasan kemampuan yang dimiliki oleh lansia sejak awal. Hanya sebagian kecil saja (48 persen) lansia yang memiliki keterampilan khusus. Keterampilan yang dimiliki oleh lansia ini antara lain berda- gang/berjualan, membuat makanan dan keterampilan lain seperti menjahit dan pertukangan. Lansia yang memiliki keterampilan dapat mengembangkan suatu usaha dan menjadi sumber penghasilan untuk menopang kebutuhan ekonomi sehari-hari.

\section{SIMPULAN}

Sebagian besar (75 persen) lansia masih bekerja dengan 34 persen jenis aktivitas (pekerjaan) sebagai pedagang/berjualan atau membuka usaha sendiri.

Sebagian besar (75 persen) lansia memiliki rata-rata peghasilan $<\mathrm{Rp}$ 1.802.700. Sebagian besar lansia masih memiliki penghasilan dibawah atau kurang dari Upah Minimum Kota/Kabupaten Surakarta 2019 dan 50 persen lansia memiliki rata-rata pengeluaran setiap bulannya sebesar Rp 1.000.000-1.500.000.

Sebagian besar (84 persen) jenis pengeluaran lansia adalah untuk memenuhi kebutuhan akan makanan dan kebutuhan lainnya seperti listik, air dan Rukun Tetangga.

\section{DAFTAR PUSTAKA}

1. Edwardi. Sampai Akhir 2018, Jumlah Penduduk Lansia Diprediksi 24 Juta Jiwa (Internet). bangkapos.com. 2018. Available from: https://bangka.tribunnews.com/2018/05 /16/sampai-akhir-2018-jumlahpenduduk-lansia-diprediksi-24-jutajiwa

2. Kementerian Kesehatan RI. Topik Utama Gambaran Kesehatan Lanjut Usia di Indonesia. 2013

3. Sumodiningrat G. Visi dan Misi pembangunan Pertanian Berbasis Pemberdayaan. Yogyakarta: IDEA; 2000.

4. Ngurah IGP. Hubungan Indeks Masa Tubuh (IMT) dan Umur Terhadap Daya Tahan Umum Mahasiswa Putra. J Pendidik Kesehat Rekreasi. 2015;1:42-7.

5. Saryono. Kumpulan instrumen penelitian kesehatan. Yogyakarta: 
Nuha Medika; 2010.

6. Arikunto. Metodelogi Penelitian. Yogyakarta: Bina Aksara; 2008.

7. Sugiyono. Metode Penelitian Kuantitatif, Kualitatif, dan $R \& D$. Bandung: Alfabeta; 2012.

8. Idris K. Gambaran tingkat ketergantungan pada pasien lansia di panti sosial tresna werdha gau mabaji kabupaten gowa. 2011; Available from: $\quad$ http://repositori.uinalauddin.ac.id/3998/1/KHARISMA IDRIS.pdf

9. Indira Permanasari S. Perempuan Lansia Lebih Banyak. kompas.com [Internet]. 2012; Available from: https://lifestyle.kompas.com/read/2012/ 04/11/19240286/perempuan.lansia.lebi h.banyak. 